\title{
On and Off Script: A Teacher's Adaptation of Mandated Curriculum for Refugee Newcomers in an Era of Standardization
}

\author{
Rabia Hos ${ }^{1, *}$ \& Beth Kaplan-Wolff ${ }^{2}$ \\ ${ }^{1}$ School of Education, University of Rhode Island, United States \\ ${ }^{2}$ Wicomico County Schools, Salisbury, MD, United States \\ *Correspondence: School of Education, University of Rhode Island 142 Flagg Road, Kingston, RI 02881, United \\ States. E-mail: rabiahos@uri.edu
}

Received: January 12, 2020

Accepted: February 7, 2020 Online Published: February 19, 2020

doi:10.5430/jct.v9n1p40

URL: https://doi.org/10.5430/jct.v9n1p40

\begin{abstract}
English Learners (ELs) make up 9.6\% of the total student population in the U.S. (National Center for Education Statistics, 2019). Students with interrupted formal education (SIFE) are a subgroup of ELs who have had at least two fewer years of schooling than their peers, and function at least two years below grade level in reading and mathematics (DeCapua, Smathers, \& Tang, 2007). To meet the demands of high stakes testing, schools have been increasingly implementing commercially published, scripted programs for ELs/SIFE (Reeves, 2010). Against this backdrop of the standards-driven and testing-based system, this article reports one of the key findings of a yearlong classroom ethnography of SIFE in an urban public secondary school in the United States, focusing on the experiences of the students and their teacher with two types of curriculum. Drawing on critical theory and culturally relevant/responsive pedagogy, the data tools include classroom observations, interviews with students and the teacher, and the videos of classroom interactions. Findings from our analysis demonstrate that the teacher played an active role in ensuring students learning through her role as a negotiator of the scripted curriculum. This study reaffirms that teachers can find ways to resist the totalizing effects of scripted curriculum.
\end{abstract}

Keywords: English Learners, Students with Interrupted Formal Education (SIFE), testing, scripted curriculum, critical theory, culturally relevant/responsive pedagogy

\section{Introduction}

Historically, the United States received more refugees than any other country until the past few years: In 2016 it accepted 84,989 refugees who were resettled in the United States by the United Nations High Commission on Refugees (Department of Homeland Security, 2016). Of these, over half are under 18 years old, and most of their educations have been interrupted during the events that caused them to become refugees. Once in the U.S. education system, older refugee children are often categorized as Students with interrupted formal education (SIFE), who have had at least two fewer years of schooling than their peers, and function at least two years below grade level in reading and mathematics (DeCapua, Smathers, \& Tang, 2007). Some adolescent SIFE are learning to read and write for the first time (Duffy, 2007).

Because of the relative newness of this population, little research has been conducted into how they experience U.S. schools under the standards-based system introduced by No Child Left Behind (NCLB), and carried forward by Every Student Succeeds Act (ESSA), the legislation that followed NCLB, in 2015. Students including SIFE are required to be tested in mathematics starting from their first year in school and in English starting a year after their arrival (Giouroukakis \& Honigsfeld, 2010). To meet the demands of high stakes testing, schools have been increasingly implementing commercially published, scripted programs for newcomer English learners (ELs), specifically for SIFE (Reeves, 2010). Schools located in high poverty areas are more likely to use scripted curriculum than other schools because of the conditions attached to their funding from the government (Reeves, 2010). One condition is to use "proved methods and strategies based on scientifically based research" (U.S. Department of Education, n.d., p. 2) and scripted curriculum are seen to provide such methods. Against this backdrop of the standards-driven and testing-based system, in this article we report one of the key findings of a yearlong classroom ethnography of SIFE in an urban public 
secondary school in the United States, focusing on the experiences of the students and their teacher with two types of curriculum. One curriculum was created by the teacher for SIFE; the second was a scripted program imposed on the classroom five months into the school year. We examined classroom observations, interviews with students and teacher, and the videos of classroom interactions. Findings from our analysis demonstrate that the teacher played an active role in ensuring students learning through her role as a negotiator of the scripted curriculum. After reviewing the research on the use of scripted curriculum with ELs, we present our theoretical framework, which draws on critical theory and culturally relevant/responsive pedagogy. Next, we describe the research site and methodology, followed by a presentation of our findings about the academic experiences of refugee SIFE and the shift we documented in the teacher's agency. We discuss implications of these findings for supporting SIFE.

\subsection{Research on Scripted Curriculum for ELS/SIFE}

Despite the widespread introduction of scripted programs for instruction as a result of NCLB, the achievement gap persists between ELs and non-ELs (Howard, 2010). In 2013, ELs demonstrated proficiency levels that were 23 to 30 percentage points below their English-speaking peers (National Center for Education Statistics, 2015). Their graduation rate is also at 61.1 percent-20 points below the national graduation rate. According to data from National Center for Education Statistics in 2015, ELs graduate from high school "at the lowest rate of all student subgroups."

Although scripted programs have been designed to address NCLB's and ESSA's goals, their use has had many negative consequences, including disengaging students from learning (Costigan, 2008). In Irvine and Larson's (2007) study of the effects of scripted reading packages on students of color who attend schools in impoverished areas, they observed that the focus was "primarily on word-sound correspondence drills and reading behaviors" rather than on "students actively interpreting text or making meaning of it orally or in writing" (p. 62).

In fact, most scripted reading curricula were designed for American students classified as special education and do not meet the needs of ELs (Gándara, Maxwell-Jolly, \& Rumberger, 2008). The scripted curricula that have been "developed for native speakers that assume an oral language foundation and access to familiar vocabulary in English" do not acknowledge the needs of ELs, much less SIFE (Harper, de Jong, \& Platt, 2008, p. 274). By ignoring ELs' cultural and linguistic needs, scripted programs do not support students learning the academic language needed for success.

In reality, many ELs/SIFE bring a wealth of knowledge and experience into the classroom that needs to be taken into consideration and valued (González, Moll, \& Amanti, 2013; Schmidt \& Lazar, 2011). This can only be done through delving into ELs/SIFE's funds of knowledge, which is a concept based on the premise that all people are competent, all people have knowledge, and people's life experiences give them that knowledge (Boske \& Benavente-McEnery, 2010). Despite the limiting nature of scripted programs, teachers have been successful in negotiating the curriculum and finding a balance between what is appropriate for their students' needs. Next, we discuss the use of culturally responsive instruction with scripted programs.

\subsection{The Use of Culturally Responsive Instruction and Funds of Knowledge with Scripted Programs}

Some educators have been able to integrate culturally responsive instruction into delivery of scripted reading programs. Nieto and Bode (2008) call for instruction that helps students' reading and writing in ways that they can draw from their backgrounds. Several studies have focused on culturally responsive reading instruction using scripted programs with African Americans and Hispanics. For example, Hefflin (2002) focused on the process of collaboration between two teachers who planned a culturally responsive literature lesson for African- American students with a scripted program. In a study of a culturally responsive teaching practices, the teacher in Powell's study (1997) made home visits to students' homes to get to know her students' cultures and families, then linked the curriculum to her students' background selecting appropriate teaching and learning materials for her students. For example, the teacher asked students to bring artifacts into the classroom so that it was more reflective of their homes such as bringing a Mexican rug to class. A culturally responsive teacher makes use of culturally appropriate texts, establishes classroom atmosphere that allows students to share their backgrounds and connects the classroom instruction to students' backgrounds.

While scripted programs have been widely used in the last decade, there are a handful of studies that examined the effect of certain scripted programs on ELs specifically. Peck and Serrano (2002) examined the effectiveness of Open Court, a scripted reading program, with ELs in elementary grades. They elicited the perspectives of 100 teacher education candidates at California State University Northridge, supervising six student teachers, and examining Open Court manuals and decodable books. They noticed that many of the teachers adapted the curriculum to meet the needs of the students. Teachers modified the lessons with realia, in order to allow students to build background 
knowledge, including vocabulary relevant to students' contexts, and going at a slower pace than the manual mandated.

According to Eisenbach (2012), teachers tend to play three different roles when the scripted curriculum is not aligned with their teaching philosophies: the accommodator, the negotiator, and the rebel. The accommodator solely relies on the scripted program despite personal conflicts with it. The accommodator can be identified by "scripted posters, student-generated scripted work, a scripted word wall, and a bulletin board containing 'unpacked' scripted assessment" (p.154) displayed around the classroom. The rebel teacher, on the other hand, does not follow the scripted curriculum but rather uses her own plans. Finally, the negotiator teacher "infuses her own ideas and beliefs into a prepackaged agenda" (p.154). The negotiator teacher finds ways to pick and choose the activities that would benefit his/her students the most and filling the "non-scripted gaps" with her "own items" (p.155). As presented here, teachers have the potential to provide culturally responsive instruction despite the mandates to use scripted curricula. Next, we describe the theoretical frameworks that informed this study.

\subsection{Theoretical Framework}

To examine the experiences of refugee adolescent SIFE's and their teacher, we draw on critical theory (Apple, 1995; 2006; 2008; 2009) and culturally relevant/responsive pedagogy (Gay, 2010; Ladson-Billings, 1995).

Scripted programs standardize both the curriculum, in terms of the knowledge purveyed, and the pedagogical practices used by the teacher. By valuing certain types of knowledge, educational systems benefit particular groups in society. As Apple (2012) asserts, "there is a selective appropriation of knowledge" in official curriculum (p. 228). Additionally, Giroux (2000) sees the imposition of commercial scripted curricula as serving a purpose: to "transform public education from a public good, benefiting all students, to a private good designed to expand the profits of investors, educate students as consumers and train young people for the low paying jobs of the new global marketplace" (p. 85).

The state's sanctioning of standard pedagogic practices enables the education system to reproduce inequality and legitimate specific types of knowledge and cultures, thus reproducing unequal relationships among different groups (Freeman, 2005; Giroux, 1995). The use of scripts in reading programs ignores the necessity for teachers to get to know students' diverse backgrounds and needs in order to teach them effectively (Gee, 2008). Despite these externally controlling forces, however, teachers must be seen as active agents rather than passive enforcers of the scripted curriculum (Apple, 1995). Indeed, teachers can challenge and resist the school system. While teachers may have curriculum imposed on them, they also can "attempt to articulate challenges to that control" (Apple, 1995, p. 95). This can be achieved through use of culturally relevant/responsive pedagogy.

Both culturally relevant pedagogy (Ladson-Billings, 1995) and culturally responsive pedagogy (Gay, 2010) agree on making use of the students' funds of knowledge in teaching and learning process. Gay (2010) describes using funds of knowledge in teaching as "building bridges of meaningfulness between home and school experiences as well as between academic abstractions and lived sociocultural realities" (pg.29). It calls for teaching in ways that consider the students' culture and prior experiences as frames of reference.

Although NCLB/ESSA regime has created systems for the strict regulation of curricula, teachers still fight back through their uses of adapted curriculum (Hursh, 2008). Our analysis of the effects of scripted curriculum in the SIFE's classroom illuminates the processes by which this control is imposed and how one teacher responds to this.

\section{Methods}

We used ethnography to study SIFE's secondary school experiences because of its emphasis on identifying and understanding the meanings that participants make of their experiences (Blommaert \& Jie, 2010). The study took place in an urban school serving secondary ELs. High school SIFE enrolling in the city school system were placed in the newcomer program at Georgetown, and later in the SIFE classroom after an academic assessment was completed in the newcomer program. Nineteen students, a certified English to Speakers of Other Languages (ESOL) teacher, and a sign language interpreter were present in the SIFE's classroom, where Author I was a participant observer throughout the school year. During this time, Author I made field notes and audio-recordings of all 140 days and video-recordings for 65 days, with 80-minute class sessions. Author I conducted two semi-structured audio-taped interviews lasting about 40 minutes with the teacher and two semi-structured audio-taped interviews lasting about 10 minutes each with seven focal students chosen based on their level of formal schooling, specifically low levels. In addition, she collected more than 200 classroom artifacts including the teacher-generated and scripted curriculum materials and student work. 
Data were analyzed using grounded theory (Charmaz, 2014), which focuses on understanding participants' "lived experience, patterns of experience and judging and appraising the experience" (Hutchinson, 1988, p. 127). The data were analyzed as they were collected following a three-stage process to coding the data: open coding, axial coding, and selective coding (Charmaz, 2014). Field notes, interview transcripts, and collected documents were read multiple times for emerging themes; codes and categories were constructed to identify findings. The effects of the teacher-generated versus the imposed scripted curriculum emerged as one of the key themes, indexing power relations in the school district, the state, and more broadly, the country under NCLB/ESSA.

\subsection{Researcher Positionality}

The desire to conduct such a study has been partly influenced by Author I's own experiences of being an adolescent EL who has gone through the high school system in the United States. Additionally, her motivation to conduct this study has also been influenced by her experience of being an ESOL teacher for SIFE and other immigrant populations for ten years. During this time, she witnessed many of the structural and curricular difficulties within the education system. She believes that the findings of this study will provide insights to the world of the refugee SIFE and allow researchers, practitioners, and policy makers to improve opportunities for this population.

\subsection{Research Site: The Secondary SIFE Program}

The study was conducted at Georgetown High School (GHS, a pseudonym), an urban secondary school with about 1200 students in grades 7 through 12 located in a metropolitan city in northeastern United States. GHS had one of the city's highest populations of ELs, housing 394 of the 3,574 ELs in the district. After being placed on the NCLB list of Schools under Review because of its low student performance, GHS had undergone various redesign processes. As part of the most recent reform, the school's Newcomer Program for refugees and immigrants was created as a sheltered ESOL program where, within grade levels, students were grouped according to their levels of formal schooling and proficiency in English (Sunnyside School District, n.d.).

SIFE were instructed by ESOL teachers in English Language Arts (ELA)/ESOL, mathematics, science, social studies, technology, and art. The focus of the classroom ethnography was a daily ESOL/ELA class. Until December (month four of the school year), the number of students in the class fluctuated between 15 and 28; when System 44, the scripted curriculum, was implemented, student numbers were restricted to 19. See Appendix for description of students.

\subsection{Participants}

As the Appendix shows, students came from three main countries of origin; their ages ranged from 13 to 18; they averaged four years of formal schooling before entering the program. The teacher, Mrs. Smith (a pseudonym), was a white, middle-class female in her mid-thirties. She held a bachelor's degree in English, and a master's degree in Teaching English to Speakers of Other Languages (TESOL) and state certification in TESOL. She had been working in the Newcomer Program for two years, not yet long enough to be tenured in the district. With teaching experience in other U.S. schools and Japan, she was dedicated, organized and creative, and highly respected by both colleagues and students.

\section{Results}

In this section, we describe the curricular decisions, classroom routines, instructional practices that the teacher created and implemented to help ELs/SIFE transition into the U.S. education system and acquire English. First, we discuss the overall curriculum and curricular decisions at the Sunnyside School District. Then we briefly describe the scripted curriculum that Mrs. Smith was asked to implement and how she adapted it in order to meet the needs of her students in the ELA classroom. We provide an overview of the use of teacher created and scripted curriculum and how they helped and/or hindered learning for ELs/SIFE in the newcomer classroom. We include a discussion of the implications of the scripted and the teacher-created curricula and conclude with students' perceptions of curricula in the classroom.

\subsection{Curricular Decisions}

In an audit by New York State Education Department of the Sunnyside School District's curriculum, it was concluded that there was a disconnection between what was taught in the school district as compared with the state standards. In order to meet the Adequate Yearly Progress (AYP), the Sunnyside School District administrators had tried out different programs in the district every school year since 2004. There was no unified curriculum for ELs. Some of the resource materials and reading programs previously tried included: High Point Series (National 
Geographic Publishing), Access, Read 180 (Scholastic), and Rosetta Stone. All of these published programs had been purchased by the district since 2005 to meet the needs of ELs/SIFE.

Before the school year started, the district purchased a scripted reading curriculum, System 44, to be used in the 'newcomer classroom' and Mrs. Smith was also trained and told by the administrators that she would be implementing this scripted reading curriculum during her ELA block. However, the computers in the classroom were not prepared until four months into the school year. In the next section we briefly introduce System 44.

\subsection{Scripted and Teacher-Created Curriculum}

\subsubsection{System 44}

System 44 is a "foundational reading program designed for the most challenged struggling readers in Grades 3-12" (Scholastic, 2009, p.1), replacing an earlier program that proved ineffective with students who "lacked the foundational phonological, decoding, and morphological skills necessary to progress in the face of increasingly challenging texts" (Scholastic, 2008, p. 3). Although System 44 is meant to be used as a stand-alone reading program, Mrs. Smith was instructed to implement it as a supplemental reading program to the ELA class. The program comprises individualized reading software for learning the sound system of English, leveled books also available on audio $\mathrm{CD}$, and individual student workbook and reading workbooks.

Because the logistics of System 44 were not put in place in a timely fashion, Mrs. Smith conducted and put in place literacy activities during the ELA block. We discuss the teacher created curriculum in the following section.

\subsubsection{Teacher-Created Curriculum}

The newcomer program lacked an established curriculum to support the ELs/SIFE. In order to prepare a curriculum that would meet the needs of her students in the classroom, Mrs. Smith conducted home visits to get to know her students before school started as well as throughout the school year. She also read through each students' cumulative folders to get information about them. Mrs. Smith's teaching philosophy focused on creating a learner-centered environment, where students worked in small groups, chose a variety of tasks, shared their work, and learned social skills. Mrs. Smith believed that SIFE needed to be explicitly taught things such as "what's going on in school, the routine, what does it mean to have a change-up schedule" (Interview, 10/24). For Mrs. Smith's students to adapt to the U.S. school culture, learning to follow consistent routines and procedure played a large role. Mrs. Smith intentionally established classroom routines to introduce structure into students' school experience and make it predictable. She believed that because of their previous life experiences "SIFE need mentally engaging lessons that have consistent structure, [and are] repetitive, and predictable" (Interview, 10/21). In the next section we describe the classroom routines and instructional practices during the ELA block.

\subsection{Classroom Routines and Instructional Practices in ELA}

The students usually arrived between 8:20 and 8:30 a.m. Mrs. Smith typically greeted the students at the door. The students then approached the plastic bins placed behind the work tables to take out their notebooks and color-coded folders for ELA. The students had different colored folders that they kept their classwork and notebooks in. They also had a separate colored homework folder to take out from the classroom. The Essential Question (EQ) was usually displayed on the SMART Board and on chart paper for students to copy in their notebooks. The EQ reflected what the teacher was focusing in her lesson for that day and what students were going to be able to answer at the end of the lesson. The purpose of having the students copy the EQ was for them to be able to refer to it throughout the lesson as well as to give them practice writing in English. At the beginning of the year, while putting this routine in place, Mrs. Smith went around the classroom to compliment students for copying the EQ. After it became a routine for after a few weeks, students automatically did this activity on their own. While students copied the EQ and settled into the classroom, school-wide announcements were made over the intercom. Oftentimes these announcements were not relevant to the students in Mrs. Smith's classroom; however, when there were general announcements that affected the students, Mrs. Smith explained the announcements and discussed them with students before she started her lessons. For example:

The principal announced that there were Regents Exam practices offered for students during the Regents week. Mrs. Smith clarified the Regents week modified schedule and what tests students were going to take after school-wide announcements:

Mrs. Smith said "What is a midterm? Is it at the end of the year, middle of the year?"

Students: "It's a middle of the year test."

Mrs. Smith: "It's a middle of the year test. Are you ready for your English midterm? Tuesday will be our English test, 
Wednesday will be our social studies test, Thursday you will go to take your math test. Your computer class PowerPoint presentation will be on Thursday during science class in the afternoon, and Friday we will have a science test in the morning. Do you have any questions about the tests next week? We have a lot of tests. Make sure you come to school." (Field notes, 1/20)

Although there would not be school for students at GHS during the Regents Exam week, students in the newcomer program were scheduled to take their mid-term exams during the week, when teachers were asked to create a modified schedule for the testing. By clarifying any confusion, Mrs. Smith anticipated that students might be confused by the changes; she thereby eased their transition to school practices.

After starting daily classes with the EQ and morning message, Mrs. Smith's teaching followed what she called a workshop model that included a pattern of a teacher-led bridge and mini-lessons. Teacher-led lessons consisted of whole class and individual work. Every day after school-wide announcements, Mrs. Smith gave students a morning message that followed the same format throughout the year. She wrote the morning message on the SMART Board and read it aloud with the students:

Good morning! Today is Friday, December 3, 2010. It's a B day. We have English and science classes today. Are you ready for the weekend?

(Video recording, 12/3)

As Mrs. Smith read the above morning message, she clarified for students what a weekend is by asking, "What is a weekend?" Mark responded, "Saturday and Sunday." As displayed in the above extracts, Mrs. Smith's morning message sometimes clarified announcements that students would need to know, repeating information for them. Other times it would allow students to briefly engage in a conversation, integrating cross-disciplinary information such as science and mathematics. Mrs. Smith's morning message that served as the bridge-activity also included an interaction component where students shared something about each other with another student and then with the whole class. For example:

What is your favorite kind of ice cream? (Field notes, 10/1)

After the above question was asked, students conversed in their groups, asking each other about what their favorite kind of ice cream was and then reported to the whole group about their friends' favorite kinds of ice cream. At the beginning of the year, in September and October, Mrs. Smith asked students simple conversational questions like the above to be discussed among each other and reported back to the whole class such as, "What sports do you like? (9/21), "Do you have any brothers or sisters? (9/22), "What time do you get up in the morning?" (9/28), "When did you come to the U.S.?" (10/5), etc. These conversational activities allowed students and the teacher to get to know each other and build community while using English.

After the bridge-activity was completed as discussed above, Mrs. Smith led a mini-lesson, oftentimes related to the language objectives of the lesson. The language objectives usually included features of English language such as capitalization, punctuation, use of prepositions, verb tenses, etc. For example:

Mrs. Smith asked students to correct the capitalization errors of the following sentences displayed on the SMART Board:

Mrs. Smith and mohamed were talking. Saen is from thailand. Saleh speaks arabic, but not french. moeh and Moew go to georgetown high school. (Field notes)

Once the sentences above that needed to be corrected were displayed on the SMART Board, Mrs. Smith asked students to volunteer to go on the board to correct the capitalization of the sentences. Mrs. Smith's use of students' names in sentences engaged students more in the lesson, for example:

Mohamed, who is usually very quiet, raised his hand to go up to correct the sentence on the board. (Field notes)

The interactive nature of the language activities using the SMART Board and personal references to individual students within the lesson made students comfortable in contributing to the lesson. Mohamed, who usually did not initiate to volunteer in class seemed to enjoy going to board to correct a sentence with his name in it.

After the bridge and mini lessons, students were asked to engage in 20-minute independent or collaborative activities in three rotations. Below we discuss the activities in these centers in detail. Here it is important to understand that knowledge of these classroom routines allowed the students to become familiar with instructional activities and aware of what Mrs. Smith and the school expected of them. Students rotated through working in an independent 
reading/writing center, a teacher-guided group, and the computer center, with six students in each rotation. The structure of the rotations differed in such a way that some required small group or partner work, and others individual work. The independent reading, listening, and writing centers set up in different parts of the room and the computer center involved students in working in the groups. Mrs. Smith had designated groups according to students' academic and linguistic proficiencies. Mrs. Smith slowly introduced independent reading in early October of the year. As students started to adjust to reading independently, then Mrs. Smith added independent writing center, listening center (where students listened to audio-books), and partner reading into the rotations. Every day, there was either independent or partner reading, writing, guided groups, and computer centers that allowed students to engage in consistent literacy practices. Figure 1 displays the rotation activities conducted throughout the year.

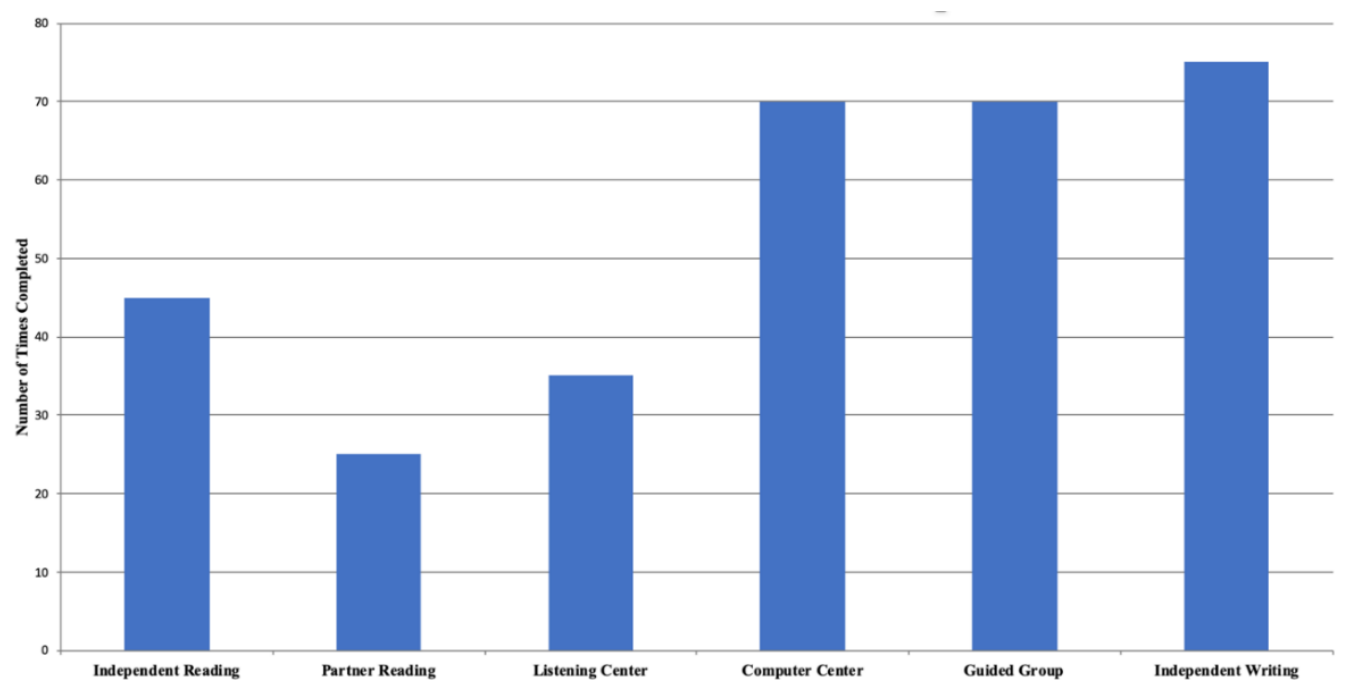

Figure 1. Distribution of Rotations

As displayed in Figure 1, most of the rotations focused on reading, writing, and computer activities, which took an approach to language development that focused on the holistic development of language practices through their application in multiple contexts. For example, the students read books and wrote summaries of them; they wrote about topics of their choice, completed charts and diagrams about lesson topics, or listened to audio-books and discussed them with each other. At the teacher guided reading center, Mrs. Smith conducted guided reading activities with students. She would have a group set of simple books at students' level and engage students in taking turns reading, discussing, and answering comprehension questions about the books read. Each 90-minute block class session ended with a five-minute sharing time where students and teacher revisited the mini-lesson. They shared examples of student work that illustrating the mini-lesson's focus and answered the Essential Question. Having consistent routines and rotations in the classroom helped ELs/SIFE to positively engage in the classroom by allowing them to reduce their anxieties (Author I, 2016; Krashen, 1982). Because the students knew what to expect from the classroom instruction on a daily basis, they were able to focus their energies on learning and contributing to the classroom.

When the computerized software for System 44 was set up four months into the school year, Mrs. Smith administered System 44's baseline Phonics Inventory test, which measures students' decoding and sight word reading fluency. Students started using System 44 at the end of January. Students' use of the individualized software replaced their rotation on the computers in one of the centers in Mrs. Smith's classroom. The System 44 print materials became the focus of another one of the independent centers, the Reading Center. In the next section we discuss the reading and writing activities that the students engaged in during the ELA block as part of their rotations.

\subsection{Reading and Writing Rotations}

Mrs. Smith believed that "reading and writing are essential to success in all of the academic content areas" (Informal conversation), therefore she created curricular activities that focused on reading and writing, which she introduced gradually. As discussed above, students spent the ELA class in three rotations engaged in reading and writing independently, in guided groups with Mrs. Smith, listening to audio-books, working on the computer, or partner 
reading.

The classroom library consisted of picture books with minimal print. As students read, they completed a simple report as shown in Figure 2.

\section{Reading Report}

Name

Date

The title of my book is

The author of the book is

This book was (easy, OK, hard) for me to read.

How was the book? Did you like it? : 0-1-2-3-4-5 :-

Draw a picture of the book.

Write a sentence about the book.

Figure 2. Reading Report

At the beginning of the year, students wrote basic sentences, yet as the year progressed, they were able to write more about the books they read.

Writing was introduced simultaneously starting from writing sentences to one paragraph essays, then eventually to three paragraph essays. At the sentence level, Mrs. Smith used a writing report, shown in Figure 3, where students practiced their handwriting and drew a picture.

\section{Writing Report}

Name

Date

Figure 3. Writing Report 


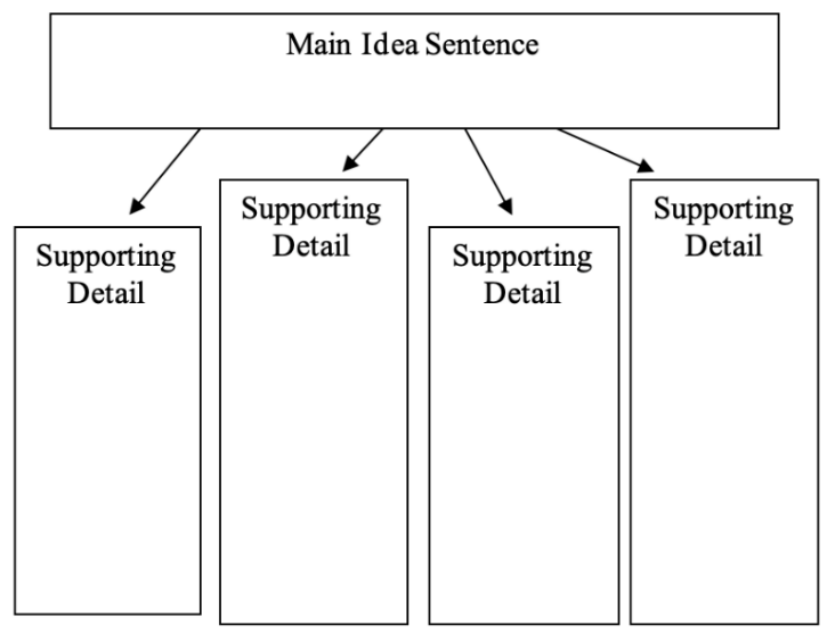

Figure 4. Main Idea and Supporting Details Graphic Organizer

After modeling how to write main ideas and details, students used the graphic organizer to start writing their paragraph. With a strong foundation writing simple sentences, students transitioned into more complex writing, working independently.

To monitor students' progress, Mrs. Smith asked students to turn in their completed writing assignments daily, then she provided feedback for each text every day. To make complex writing easier, Mrs. Smith provided students with a checklist to use before submitting their assignments, as shown in Table 1.

Table 1. Mrs. Smith’s Writing Checklist

Mrs. Smith's Writing Checklist

1 Does my paragraph have an introduction (a beginning) that tells about what the paragraph is about?

2 Does my paragraph have three or more body sentences (the middle) that tell about my ideas?

3 Does my paragraph have a conclusion (an end) that tells a little more about the introduction?

4 Do my sentences have capital letters at the beginning of sentences? Do I have capitals for names and other important words $(\mathrm{ABC})$ ?

$5 \quad$ Do I use periods (.), exclamation points (!), and question marks (?) ?

$6 \quad$ Did I check my spelling?

7 Did I draw a picture to tell about my paragraph?

8 Did I read my paragraph to see if it sounds right?

Students also used the writing checklist during the process of peer-reviewing each other's writing. For the last part of the writing checklist, Mrs. Smith asked students to read their essays to another peer in the classroom and make sure it sounds right. While one student read his/her own essay, the other student listened and then provided feedback.

Reading and writing were the centerpiece of Mrs. Smith's pedagogy for literacy and English language learning, through which she scaffolded students into engaging with challenging texts. Mrs. Smith encouraged students to be creative and write about a variety of topics they were interested in. One day in April as students wrote on these topics during class, they were enthusiastic about finishing their essays to be shared during class time, as the topics were meaningful to them. By May, students could write a three-paragraph essay that asked students to think critically about issues in their lives. For example, Sunny wrote about the poor conditions at his house and what he wanted to change about them:

Today I want to talk about my house. I want to change my windows, my bathroom, and my kitchen. In my house there are many windows with glass that is broken. I call the landlord but they do not come to my 
house. I want to change my bathroom because it's too small, we need a bigger bathroom. I also want to change my kitchen because it's too small. We need a bigger kitchen to make things. There is also a leak on my water tap. If I can change these things, it would be great!

After providing feedback on drafts, Mrs. Smith allowed students to edit and finalize their essays. Students also shared their essays during presentation time in class. After one such presentation, during the writing rotation, Mrs. Smith encouraged Sunny to call his landlord about his housing conditions, and offered to help him. Sunny said that he was going to call his landlord after school that day.

Mrs. Smith's curriculum and pedagogy focusing on literacy gave ELs/SIFE an opportunity to write critically about real-life issues, which made the students feel empowered to take initiative about problems they faced in real life. The students learned through the establishment of routines, meaningful instruction that met both content and language objectives, and the opportunity to write on meaningful topics. Mrs. Smith's approach to teaching ELs was consistent with best practices for ELs. As students in Mrs. Smith's classroom had different backgrounds and schooling experiences, by asking students to work cooperatively, she created communities of learners (Rogoff, 1994). She had differentiated work for students and asked students to work cooperatively to support each other. Mrs. Smith made language and concepts more comprehensible and memorable through the visual scaffolds she consistently integrated into her lessons. She also built on students' backgrounds as she introduced new vocabulary and concepts. Although her curriculum and instructional practices seemed to work well for the ELs/SIFE in her classroom, there were limitations that hindered Mrs. Smith's ability to offer more rigorous and grade level content for the students. We discuss the implications of the scripted and the teacher-created curricula in the next section. First, we discuss three themes from our analysis of the System 44 curriculum: A focus on phonics rather than meaning making, student disengagement and increased competition, and restricted teacher agency and students' perceptions of the curricula.

\subsection{Implications of Scripted and Teacher-Created Curricula}

\subsubsection{Focus on Phonics}

The focus of System 44 as a reading program was on phonics. The ELs/SIFE in Mrs. Smith's classroom had trouble making meaning from the words the program focused on, which were decontextualized and unrelated to student experience. When students started to navigate the components of System 44, they had a difficult time during individualized computer time and independent reading time. It took some time for the students to remember their username and passwords. The directions on the computer were not explicitly explained. They also encountered technical difficulties with the computer. As Sunita reported, "System 44 is hard to understand" (Interview, 3/3). Indeed, we observed one of the students, Saleh, working on the computer software: as the computer presented words to be pronounced and recorded through a microphone:

The word "hum" appears; Saleh reads: "him."

The word "mud" appears; Saleh reads: "mad."

The word "fin" appears; Saleh reads: "fan." (Field notes, 5/24)

Despite incorrectly pronouncing all of the words presented and not comprehending the text at the end of the unit, Saleh was automatically passed by System 44 to the next level of work on the computer. And although as an administrator of System 44, Mrs. Smith was able to listen to Saleh's mistakes, there was not a way to have him to re-do the section to improve his pronunciation. Thus, as Mrs. Smith noted, the software was limiting:

I think [the students] could have maybe understood it better if I was able to look and see where they were at and then model it for them on another computer. The [publisher's] rep said we can't jump into the software, so there was no way for me to model. The software has a lot of limitations. (Interview, 5/25)

Finally, although some students were able to decode the text presented on the computer, when their comprehension was evaluated in System 44's progress reports, most scored low (see Appendix for comprehension scores). Very few SIFE made progress in literacy and learning English once System 44 was implemented according to the System 44 assessments. Three students who had more previous formal education made the most progress decoding words, while those with less formal education made minimal progress.

\subsubsection{Disengagement and Increased Competition}

Once System 44 was implemented, some students in Mrs. Smith's class became disengaged from classroom activities for various reasons. Many of them encountered multiple technical problems with System 44, from ongoing difficulties logging in to the computer to problems with the microphones not picking up their voices. As a result, during the year many students lost almost half of the 20 minutes of their allocated computer time trying to resolve 
these difficulties, with no technical support provided by the school. In addition, we observed a group of young men regularly went to the bathroom during System 44 computer time. In one month, for example, Saleh, Hasan, Ray, and Kurung took an average five minutes of the computer time to visit the bathroom (Field Notes, 5/20).

In contrast to the disengaged students, as some of the higher-level students realized that there were different levels in System 44, they started competing with each other. For example, Mark and Moew sat next to each other during computer time and watched each other's progress as they raced through the program to get ahead. This increased competition changed how students treated each other prior to System 44, when they had been more cooperative and respectful. For example, Moew started to be less sensitive about being a part of the community but started to act like he was superior to others and this was evident when he kept pointing to his superior progress on the computer while sitting next to Mark (Field notes, 5/24). When Haoh asked Moew for help one day, Moew kept working on his computer and disregarded Haoh's request for help, instead laughed at him (Field notes, 5/25). The decontextualized activities of the System 44 computer program thus negatively affected students' learning and interactions with each other. In addition to the individualized computer software that students used during computer rotation, Mrs. Smith also made use of the reading library and the student workbooks. The decodable workbook and the reading workbook were used during Mrs. Smith's guided work with students. Although each student was assigned a workbook, they did not make use of it extensively. Mrs. Smith decided that the workbooks were not helpful, as "the vocabulary was not contextual." The following example of a decodable reading passage used during guided instruction center illustrates this problem: "Jen is a jock. Jen met Jin on a run. Jin asked Jen to wed. Jen cannot wed yet. Jen is in a jam. Jen jets" (Field notes, 5/24). The library books were also available on CD so students either listened to the audio while following along the book, or read the books in the library during independent reading center.

\subsubsection{Restricting Teacher Agency}

Finally, our analyses showed that the imposition of the scripted curriculum had direct consequences for the autonomy and professionalism of the teacher. Mrs. Smith was forced to limit time for activities that yielded results for the ELs/SIFE in her classroom such as reading books at students' level and writing based on open-ended prompts. Instead she had to use the decodable library books provided by System 44 . The use of these materials impinged on Mrs. Smith's autonomy, creativity, and efficacy. After trying to use the scripted texts during the guided instruction center, Mrs. Smith used only some of System 44's instructional activities such as the independent reading, listening to audios, and computer software in the ELA class. Even though Mrs. Smith voiced her concerns about the decodable library books, feeling that they were not appropriate for SIFE, she was asked to continue to use these materials. According to Mrs. Smith, System 44's reading library and workbooks:

Aren't for these kids. The representative keeps saying that all these books are decodable but Haoh can decode and read all the words in these books but he has no clue what he is reading. This program shouldn't be used with SIFE. (Interview, 5/25)

Although Mrs. Smith was required to implement System 44, as much as possible she contextualized learning for ELs/SIFE in relation to their backgrounds. When she was supposed to be following the scripted curricula, she mostly focused on contextual reading and writing in order to prepare her students for academic settings. She was able to shift away from the scripted curriculum through implementing parts of System 44 while also teaching her own curriculum that focused on reading and writing. She was a negotiator of the scripted curriculum rather than accommodator or a rebel.

System 44 failed to respond to the SIFE's unique cultural and linguistic needs and interests. Although the technological component of the System 44 seemed to motivate students to keep using the software, many students were intrinsically motivated to learn English, therefore engaged in activities that Mrs. Smith set up for them. In the next section, we discuss the students' perceptions of curricula in the classroom.

\subsection{Students' Perceptions of Curricula in the Classroom}

System 44 was designed to help EL's linguistic needs by first teaching them about the English language system, including decoding, spelling, word patterns and word meaning. However, ELs/SIFE needed additional guidance from Mrs. Smith in order to understand the language system through clear explanation. Although System 44 was to be followed independently, Mrs. Smith implemented guided reading practice with the different groups of students during the rotations.

The findings indicated that System 44 provided some strategies for understanding English language usage for ELs/SIFE in the areas of decoding of words and speaking more English. For example, Haoh said that System 44 "helped to speak more English" (Haoh, 5/26). Than also believed that System 44 "provided better pronunciation" 
(Than, 3/7). Perry also believed that System 44 "helped to learn to read sounds" (Perry, 5/26).

On the other hand, almost all of the students reported that the independent use of the audio-CD's was not helpful. For example, both Ray and Haoh reported that the System 44 books and the CD's did not "help learn to read" (Ray \& Haoh, 5/26). In contrast, they thought that "reading Mrs. Smith's books helped" (5/26). The students enjoyed reading non-System 44 books that met their individual interests and reading levels. In fact, this was largely due to the fact that System 44 books did not correspond the levels and background of the ELs/SIFE. For example, Perry and Saleh both commented that they do not like to read the System 44 books. Saleh said that, "Sometimes I don't like to read books over there" (Saleh, 5/25). Additionally, for Saleh and Moeh and other students, "doing system 44 with Mrs. Smith helped to learn more English and read better" (Saleh \& Moeh, 5/26).

Aside from System 44 materials, most of the students enjoyed reading and writing. Moeh and Haoh thought that "writing about different topics helped to get better at writing in English" (Moeh \& Haoh, 5/27). All of the students thought that Mrs. Smith's guided reading and writing rotation helped them to learn more English. When they were set to read independently, the students reported that they needed more guided support for comprehension. The students also believed that the conversational interactions in the classroom helped them to speak more English. Than indicated that "I get better at speaking out and sharing" (Than, 5/27).

While implementation of System 44 was not a choice for Mrs. Smith, she successfully managed to implement different components of the software along with her own curriculum to meet the needs of the ELs/SIFE. The classroom observations and students' perceptions indicate that System 44 did not meet the needs SIFE who need additional support and guidance. Even though students found some of System 44 components helpful, overall, they felt that Mrs. Smith's materials were better comprehensible for them and helped them learn more English.

While the scripted curriculum was limited, Mrs. Smith's approach to designing curriculum that met the needs of the refugee ELs/SIFE created a positive learning environment for students and helped them adjust to the school in the United States. Although the content knowledge for students was limited, Mrs. Smith's emphasis on literacy building through reading and writing helped students to gain academic knowledge in reading and writing, which would help them once they transition into the mainstream classrooms.

\section{Discussion}

The findings of this study demonstrate that teacher-created curriculum with meaningful activities contributed to positive adaptation of SIFE into the U.S. education system. Using learner-centered pedagogy, Mrs. Smith considered students' educational and cultural backgrounds by valuing their thoughts and values and the level of their knowledge of English and academic content. Not only did the teacher created curriculum provide differentiation that was beneficial to students, it also provided the teacher with the ability to manage learning activities. Through the planning of activities that appealed to the diverse interest of students and took into effect the different styles of learning, Mrs. Smith promoted language and academic development. Students made progress under her curriculum; by the end of the year all students were able to write three-paragraph essays on meaningful topics and able to read simple books and comprehend to it. With the use of authentic writing lessons, many of them showed growth in writing about various topics. The use of consistent routines and modelling of classroom tasks supported SIFE's transition into their secondary schooling in the U.S. and provided opportunities for students to interact with each other in meaningful ways. At the same time, the teacher acted creatively and autonomously in response to her knowledge of students.

In contrast, under System 44 students were refocused to skills-driven work that was decontextualized from relevant contexts and instead focused on tasks unrelated to their lives. In parallel, the teacher's role was reduced primarily to being an administrator of the system. However, Mrs. Smith as the "negotiator" (Eisenbach, 2012) of the scripted curriculum package picked and chose what was best for her students. Overall, System 44 exemplifies what Apple (1990) calls a "teacher-proof curriculum" (p. 52). System 44's instructional material is prescribed, with student workbooks, levelled library books, and software that trains students on phonics rather than supporting meaning making. Apple (2008) notes that scripted curricula include "goals, strategies, tests, textbooks, worksheets, and appropriate student responds" within the program so the teacher becomes the moderator of the system rather than a critical theorizer about how the curriculum can meet student needs.

This study reaffirms that teachers can find ways to resist the totalizing effects of scripted curriculum. By resisting use of the scripted curriculum at key pedagogical moments, Mrs. Smith actively responded to systems that disempowered her and her students (Aronowitz \& Giroux, 1991). For example, she was able to connect with Sunny about his home 
life as a result of a teacher-created writing assignment. The creativity and community-centered mentality that Mrs. Smith inspired in her students made for truly individualized instruction that would not have been possible with a limited scripted curriculum. She used culturally responsive instruction that considered students' funds of knowledge (Gay, 2010; Moll, Amanti, Neff, \& González, 1992). Her professional and personal values allowed her to implement what she felt was best for her students even though it meant resisting structures within the school, despite not yet having attained tenure in the school district. This study supports the conclusion that teachers who resist the scripted curriculum are engaged in purposeful activities that represent their professional identity and beliefs about learning (Eisenbach, 2012). However, not all teachers have the courage of their convictions and are comfortable risking their own positions by disregarding school mandates.

Ultimately, replacing high-quality teaching that responds to the specific needs of SIFE with commercial, scripted curriculum works to reproduce the marginalized status of ELs/SIFE in the United States. As Irvine and Larson (2007) argue, packaged scripted curricula "support particularly disadvantaging pedagogies in districts serving primarily poor, working-class, and language minority students" (p. 67). Many SIFE live in highly segregated and impoverished areas; they are already at a disadvantage because of their prior schooling experiences and socioeconomic status (Curry, 2007; Hos, 2016). For these students, the time wasted on scripted reading curriculum is time they can ill afford in their efforts to catch up on education. Despite past traumatic experiences, most SIFE are ambitious, resilient, and diligent about learning English (Hos, 2014). They care about their studies. To help these students succeed, schools must tailor their pedagogical techniques to what works best for the adolescent refugee SIFE while assisting them in linking their previous knowledge and experiences, that is, in making connections to their new knowledge.

\section{References}

Apple, M. W. (2012). Knowledge, Power, and Education: The Selected Works of Michael W. Apple. Routledge. https://doi.org/10.4324/9780203118115

Apple, M. W. (2009). Global crises, social justice and education. Routledge. https://doi.org/10.4324/9780203861448

Apple, M. W. (2008). Controlling the work of teachers. In D.J. Flinders \& S.J. Thornton (Eds.), The curriculum studies reader (pp. 183-197). Routledge.

Apple, M. W. (1995). Education and Power (2nd ed.). Routledge.

Apple, M. W. (1990) Ideology and curriculum. New York: Routledge.

Aronowitz, S., \& Giroux, H. (1991). Postmodern education: Politics, culture and social criticism. University of Minnesota Press.

Hos, R. (2016). Caring is not enough: Teachers' Enactment of Ethical Care for Adolescent Students with Limited or Interrupted Formal Education (SLIFE) in a Newcomer Classroom. Education and Urban Society, 48, 479-503.

Hos, R. (2016-OnlineFirst). The Lives, Aspirations, and Needs of Refugee and Immigrant Students with Interrupted Formal Education (SIFE) in a Secondary Newcomer Program. Urban Education. https://doi.org/10.1177/0042085916666932

Blommaert, J., \& Jie, D. (2010). Ethnographic fieldwork: A beginner's guide. Multilingual Matters. https://doi.org/10.21832/9781847692962

Boske, C., \& Benavente-McEnery, L. (2010). Taking it to the streets: A new line of inquiry for households, schools, and communities. Journal of School Leadership, 20(3), 369-398. https://doi.org/10.1177/105268461002000306

Charmaz, K. (2014). Constructing grounded theory (2nd ed.). Sage.

Costigan, A. T. (2008). Canaries in the coal mine: Urban rookies learning to teach language arts in "high priority" schools. Teacher Education Quarterly, 35(2), 85-102.

Curry, M. J. (2007). A "head start and a credit:" Analyzing cultural capital in the basic writing/ESOL classroom. In J. Albright \& A. Luke (Eds.), Pierre Bourdieu and literacy education (pp. 275-295). Lawrence Erlbaum.

DeCapua, A., Smathers, W., \& Tang, L. (2007). Schooling, interrupted. Educational Leadership, 64, 40-46.

Duffy, J. N. (2007). Writing from these roots: Literacy in a Hmong American community. University of Hawaii Press.

Eisenbach, B. B. (2012). Teacher belief and practice in a scripted curriculum. The Clearing House: A Journal of Educational Strategies, Issues and Ideas, 85(4), 153-156. https://doi.org/10.1080/00098655.2012.663816 
Freeman, E. (2005). No Child Left Behind and the denigration of race. Equity and Excellence in Education, 38, 190-199. https://doi.org/10.1080/10665680591002560

Gándara, P., Maxwell-Jolly, J., \& Rumberger, R. (2008). Resource needs for English learners: Getting down to policy recommendations. University of California Santa Barbara: Linguistic Minority Research Institute.

Gay, G. (2010). Culturally responsive teaching: Theory, research, and practice (2nd ed.). Teachers College Press.

Gee, J. P. (2008). Social linguistics and literacies: Ideologies in discourses. Routledge. https://doi.org/10.4324/9780203944806

Giouroukakis, V., \& Honigsfeld, A. (2010). High-stakes testing and English Language Learners: Using Culturally and Linguistically Responsive Literacy Practices in the High School English Classroom. TESOL Journal, 1(4), 470-499. https://doi.org/10.5054/tj.2010.240193

Giroux, H. A. (2000). Stealing innocence: Corporate culture's war on children. Palgrave. https://doi.org/10.1007/978-1-137-10916-3

González, N., Moll, L. C., \& Amanti, C. (Eds.). (2013). Funds of knowledge: Theorizing practices in households, communities, and classrooms. Routledge.

Harper, C. A., deJong, E. J., \& Platt, E. J. (2008). Marginalizing English as a second language teacher expertise: The exclusionary consequence of No Child Left Behind. Language Policy, 7, 267-284. https://doi.org/10.1007/s10993-008-9102-y

Hefflin, B. R. (2002). Learning to develop culturally relevant pedagogy: A lesson about cornrowed lives. Urban Review, 34, 231-250. https://doi.org/10.1023/A:1020603323594

Howard, T. C. (2010). Why race and culture matter in schools: Closing the achievement gap in America's classrooms. Teachers College Press.

Hursh, D. (2008). High-stakes testing and the decline of teaching and learning: The real crisis in education. Rowman \& Littlefield.

Hutchinson, S. A. (1988). Education and grounded theory. In R.R. Sherman \& R.B. Webb (Eds.), Qualitative research in education: Focus and methods (pp.123-40). Falmer.

Irvine, P. D., \& Larson, J. (2007). Literacy packages in practice: Constructing academic disadvantage. In J. Larson (Ed.), Literacy as snake oil: Beyond the quick fix (2nd ed.). (pp. 49-72). Lang.

Krashen, S. D. (1982). Principles and practice in second language acquisition. Pergamon.

Ladson-Billings, G. (1995). Toward a theory of culturally relevant pedagogy. American Educational Research Journal, 32(3), 465-491. https://doi.org/10.3102/00028312032003465

Moll, L.C., Amanti, C., Neff, D., \& González, N. (1992). Funds of knowledge for teaching: Using a qualitative approach to connect homes and classrooms. Theory into Practice, 31(2), 132-141. https://doi.org/10.1080/00405849209543534

National Center for Education Statistics. (2015). Achievement gap narrows as high school graduation rates for minority students improve faster than rest of nation [Press release]. Retrieved from http://www.ed.gov/news/press-releases/achievement-gap-narrows-high-schoolgraduation-ratesminority-students -improve-faster-restnation

National Center for Education Statistics. (2019). English language learners in public schools. Retrieved from https://nces.ed.gov/programs/coe/indicator_cgf.asp

Nieto, S., \& Bode, P. (2008). Affirming diversity: The sociopolitical context of multicultural education (5th ed.). Pearson Education, Inc.

No Child Left Behind Act of 2001, Pub. L. No. 107-110, §115, Stat. 1425 (2002).

Peck, S., \& Serrano, A. M. (2002). Open court and English language learners: Questions and strategies. Paper presented at the Annual Meeting of the American Association for Applied Linguistics, Salt Lake City, UT, April, 6-9.

Powell, R. (1997). Then the beauty emerges: A longitudinal case study of culturally relevant teaching. Teaching and Teacher Education, 13(5), 467-484. https://doi.org/10.1016/S0742-051X(96)00052-2

Reeves, J. (2010). Teacher learning by script. Language Teaching Research, 14(3), 241-258. 
https://doi.org/10.1177/1362168810365252

Rogoff, B. (1994). Developing understanding of the idea of communities of learners. Mind, Culture, and Activity, 1(4), 209-229.

Schmidt, P. R., \& Lazar, A. M. (Eds.). (2011). Practicing what we teach: How culturally responsive literacy classrooms make a difference. Teachers College Press.

Scholastic. (2008). Foundation paper: Supporting special education students with System 44. Retrieved from http://www.scholastic.com/economicrecovery/pdfs/IDEASpEd_System44_0316.pdf

Scholastic. (2009). Preliminary evidence of effectiveness: System 44. Formative Research Paper. Retrieved from http://teacher.scholastic.com/products/research/pdfs/S44_Formative_Singles.pdf

Sunnyside School District. (n.d.).

U.S. Department of Education. (n.d.). Comprehensive school reform. Retrieved from http://www2.ed.gov/programs/compreform/2pager.html

U.S. Department of Homeland Security. (2016). Refugees and asylees: 2016. Retrieved from https://www.dhs.gov/sites/default/files/publications/Refugees_Asylees_2016_0.pdf

\section{Appendix}

SIFE Classroom Demographics

\begin{tabular}{|c|c|c|c|c|c|}
\hline $\begin{array}{c}\text { Student } \\
\text { (Pseudonym) }\end{array}$ & Age & $\begin{array}{c}\text { Country of } \\
\text { Origin }\end{array}$ & $\begin{array}{c}\text { Years of Prior } \\
\text { Schooling }\end{array}$ & $\begin{array}{c}\text { System } 44 \text { Oral Reading } \\
\text { Fluency Score (of a } \\
\text { possible 6) }\end{array}$ & $\begin{array}{c}\text { System } 44 \\
\text { Comprehension Score } \\
\text { (of a possible 100) }\end{array}$ \\
\hline Ray & 15 & Burma & 4 & 1.0 & 47 \\
\hline Libby & 13 & Burma & 5 & 1.0 & 72 \\
\hline Moey & 13 & Burma & 4 & 2.0 & 74 \\
\hline Haoh & 18 & Burma & 4 & 2.0 & 52 \\
\hline Ehan & 13 & Burma & 4 & 1.0 & 64 \\
\hline Mark & 15 & Burma & 5 & 2.0 & 91 \\
\hline Moew & 15 & Burma & 5 & 3.0 & 88 \\
\hline Than & 15 & Burma & 3 & 1.0 & 56 \\
\hline Phan & 16 & Burma & 4 & 3.0 & 87 \\
\hline Laoh* & 18 & Burma & 0 & N/A & N/A \\
\hline Saen & 17 & Burma & 3 & 1.0 & 58 \\
\hline Dani & 14 & Nepal & 5 & 3.0 & 90 \\
\hline Perry & 17 & Nepal & 5 & 1.0 & 56 \\
\hline Sunita & 15 & Nepal & 5 & 2.0 & 67 \\
\hline Sunny & 13 & Nepal & 4 & 2.0 & 37 \\
\hline Kurung & 16 & Nepal & 5 & 2.0 & 44 \\
\hline Hasan & 17 & Yemen & 6 & 1.0 & 77 \\
\hline Saleh & 16 & Yemen & 5 & 1.0 & 50 \\
\hline Mohamed & 17 & Yemen & 5 & 2.0 & 70 \\
\hline
\end{tabular}

*A deaf student assisted by a sign language interpreter who was always present. The student was not able to use System 44 because she worked with a sign language interpreter during this time. 